Research article

Open Access

\title{
Expression and regulation of neurotrophins in the nondegenerate and degenerate human intervertebral disc
}

\author{
Devina Purmessur, Anthony J Freemont and Judith A Hoyland
}

\author{
Tissue, Injury and Repair, School of Clinical and Laboratory Sciences, Faculty of Medical and Human Sciences, Stopford Building, Oxford Road, The \\ University of Manchester, Manchester, M13 9PT, UK \\ Corresponding author: Judith A Hoyland, judith.a.hoyland@manchester.ac.uk
}

Received: 10 Jun 2008 Revisions requested: 11 Jul 2008 Revisions received: 23 Jul 2008 Accepted: 27 Aug 2008 Published: 27 Aug 2008

Arthritis Research \& Therapy 2008, 10:R99 (doi:10.1186/ar2487)

This article is online at: http://arthritis-research.com/content/10/4/R99

(c) 2008 Purmessur et al.; licensee BioMed Central Ltd.

This is an open access article distributed under the terms of the Creative Commons Attribution License (http://creativecommons.org/licenses/by/2.0), which permits unrestricted use, distribution, and reproduction in any medium, provided the original work is properly cited.

\begin{abstract}
Introduction The neurotrophins nerve growth factor (NGF) and brain-derived neurotrophic factor (BDNF) have been identified in the human intervertebral disc (IVD) and have been implicated in the mechanisms associated with nerve ingrowth and nociception in degeneration of the IVD. The aim of the current study was to investigate an association between neurotrophin expression in the IVD and the severity of disc degeneration, including the effect of disc-related proinflammatory cytokines on neurotrophin and neuropeptide expression in cells derived from the human IVD.
\end{abstract}

Methods Immunohistochemical analysis was performed to examine the expression of NGF, BDNF and their high-affinity receptors Trk-A and Trk-B in human IVD samples, divided into three categories: non-degenerate, moderate degeneration and severe degeneration. In order to study the effect of disc-related cytokines on neurotrophin/neuropeptide gene expression, nucleus pulposus cells derived from non-degenerate and degenerate IVD samples were seeded in alginate and were stimulated with either IL- $1 \beta$ or TNF $\alpha$ for 48 hours. RNA was extracted, cDNA was synthesised and quantitative real-time PCR was performed to examine the expression of NGF, BDNF and substance $P$.
Results Immunohistochemistry showed expression of NGF and BDNF in the native chondrocyte-like cells in all regions of the IVD and in all grades of degeneration. Interestingly only BDNF significantly increased with the severity of degeneration $(P<$ 0.05). Similar expression was observed for Trk-A and Trk-B, although no association with disease severity was demonstrated. In cultured human nucleus pulposus cells, stimulation with IL-1 $\beta$ led to significant increases in NGF and BDNF gene expression $(P<0.05)$. Treatment with TNF $\alpha$ was associated with an upregulation of substance $P$ expression only.

Conclusion Our findings show that both the annulus fibrosus and nucleus pulposus cells of the IVD express the neurotrophins NGF and BDNF, factors that may influence and enhance innervation and pain in the degenerate IVD. Expression of Trk-A and Trk-B by cells of the nondegenerate and degenerate IVD suggests an autocrine role for neurotrophins in regulation of disc cell biology. Furthermore, modulation of neurotrophin expression by $\mathrm{IL}-1 \beta$ and modulation of substance $\mathrm{P}$ expression by $\mathrm{TNF} \alpha$, coupled with their increased expression in the degenerate IVD, highlights novel roles for these cytokines in regulating nerve ingrowth in the degenerate IVD and associated back pain.

\section{Introduction}

Low back pain is a widespread and incapacitating disorder of significant social and economic importance [1]. Degeneration of the intervertebral disc (IVD) has been implicated in the pathogenesis of chronic low back pain [2], and is characterised by increased degradation of the extracellular matrix coupled with an ingrowth of blood vessels and nerves $[3,4]$ into the normally avascular and aneural tissue. Indeed, we have shown an association between the painful degenerate IVD and nerve ingrowth [5]. The mechanisms underlying innervation into the degenerate human IVD, however, are largely unknown. Studies by Johnson and colleagues have demonstrated that the extracellular matrix component aggrecan, derived from the healthy IVD, has an inhibitory effect on neurite outgrowth [6]. Likewise, such an inhibitory effect has also been demonstrated in an ovine annular model of disc degeneration in which

BDNF = brain-derived neurotrophic factor; DMEM = Dulbecco's modified Eagle's media; FCS = foetal calf serum; IAF = inner annulus fibrosus; IL = interleukin; IVD = intervertebral disc; NGF = nerve growth factor; NP = nucleus pulposus; OAF = outer annulus fibrosus; PBS = phosphate-buffered saline; $\mathrm{PCR}=$ polymerase chain reaction; TNF = tumour necrosis factor. 
depletion of the proteoglycan content was associated with an increased nerve ingrowth into the IVD [7].

The normal healthy IVD is largely aneural. Anatomical studies by Jackson and colleagues and by Bogduk and colleagues have demonstrated innervation of only the superficial outer layers of the annulus fibrosus, with the central core of the IVD completely lacking nerves $[8,9]$. This is supported by the work of Fagan and colleagues, who have demonstrated innervation of both the perianular region of the IVD as well as the central region of endplate above the nucleus pulposus (NP) [10]. Within the degenerate IVD, however, nerves have been shown to penetrate both the inner annulus fibrosus (IAF) and the NP. Importantly, these innervating fibres have been shown to express both the neural growth-associated marker GAP43 and the pain-associated neuropeptide substance $P$ [5].

Additional studies investigating innervation in the degenerate IVD have also demonstrated expression of Trk-A, the highaffinity receptor for nerve growth factor (NGF), on ingrowing nerves - indicating that such nerves are NGF sensitive [4]. This is supported by Aoki and colleagues, who have identified NGF-responsive nerve fibres as the predominant neuronal subtype innervating the peripheral regions of the healthy annulus fibrosus [11]. Studies by Ohtori and colleagues have also demonstrated that a number of the neurons innervating the rat IVD were immunoreactive for brain-derived neurotrophic factor (BDNF), a modulator of pain-associated processes in the dorsal horn of the spinal cord [12].

Neurotrophins are growth and survival factors, associated mainly with neuronal development, function and nociception [13]. They are located primarily within the central and peripheral nervous systems, and they consist of a family of four principal members: NGF, BDNF, neurotrophin 3 and neurotrophin $4 / 5$. Both NGF and BDNF have been identified in non-neural cells of healthy and diseased connective tissue such as human cartilage and bone, and, interestingly, recent studies have highlighted a possible role for neurotrophins in the IVD [1417]. For example, Johnson and colleagues demonstrated stimulation of neurite outgrowth by soluble mediators produced by degenerate disc cells, mediators they hypothesised to be neurotrophic factors [18]. Additionally, NGF has been identified in association with the blood vessels growing into the degenerate IVD [4], and also in the rounded chondrocyte cells of the annulus fibrosus [16]. More recently, Abe and colleagues have confirmed this and have also shown both expression and synthesis of NGF in NP cells isolated from the human IVD [19].

As well as NGF expression, microarray analysis of human disc cells subjected to hyperosmotic stimuli has identified expression and upregulation of BDNF [20]. Additionally, in a recent study Gruber and colleagues showed expression of BDNF in human IVD cells, with BDNF gene expression in annulus fibrosus cells positively correlating with increasing degeneration
[21]. Whether both NGF and BDNF are upregulated in the degenerate IVD, and as such play a key role in innervation and the pathogenesis of low back pain, however, remains to be determined.

The neurotrophins NGF and BDNF function principally through their high-affinity receptors Trk-A and Trk-B. Indeed, both receptors have been identified in cells of the musculoskeletal system, and more recent studies have demonstrated Trk-A and Trk-B expression in human disc cells [14-17,19,21]. Studies investigating a role for neurotrophins in the pathogenesis of osteoarthritis have shown upregulation of both NGF and Trk-A in osteoarthritic chondrocytes [15]. Nevertheless, expression of Trk-A and Trk-B by human disc cells in terms of disease pathology has yet to be fully examined.

A role for the proinflammatory cytokines TNF $\alpha$ and IL-1 $\beta$ in innervation of the IVD [22] and in degeneration of the IVD has been demonstrated by a number of authors [23-25]. Additionally these cytokines have been shown to regulate neurotrophin expression in non-neuronal cells. Studies by Kemi and colleagues have demonstrated upregulation of NGF and BDNF in bronchial smooth muscle cells after treatment with IL-1 [26]. Similarly, in synovial fibroblasts isolated from patients with osteoarthritis, both IL-1 $\beta$ and TNF $\alpha$ were shown to increase NGF synthesis and release [27]. Evidence to support a role for IL-1 $\beta$ and TNF $\alpha$ in the modulation of neurotrophin expression in the IVD comes from studies by Abe and colleagues, who demonstrated an increase in NGF gene expression and protein secretion after NP cells (cultured in monolayer) were treated with IL-1 $\beta$ and TNF $\alpha$ [19].

Work to date therefore supports a role for neurotrophins in the biology of innervation in the IVD, the function of which may be regulated by proinflammatory cytokines known to be upregulated during IVD degeneration [23-25]. Based on this knowledge we hypothesised that expression of the neurotrophins NGF and BDNF increases with disc degeneration and that they are regulated by IL-1 $\beta$, which also increases with the severity of degeneration. Using immunohistochemistry we have therefore investigated NGF and BDNF expression, including expression of the receptors Trk- $A$ and Trk-B, in nondegenerate, moderately degenerate and severely degenerate human IVD tissue, and we have examined the effects of IL-1 $\beta$ and TNF $\alpha$ on neurotrophin expression in non-degenerate and degenerate disc cells (seeded in a three-dimensional matrix).

\section{Materials and methods NGF, BDNF, Trk-A and Trk-B protein expression in the nondegenerate and degenerate human IVD}

Human IVD tissue was obtained at surgery/postmortem, and ethical consent was obtained from the local ethical committees together with informed consent from the patient or relatives. IVD tissue samples were fixed overnight in $4 \%$ 
paraformaldehyde/PBS at $4^{\circ} \mathrm{C}$, processed to paraffin wax and $5 \mu \mathrm{m}$ sections prepared.

For immunohistochemical analysis, a total of 15 patient samples were used (age range 37 to 75 years): non-degenerate IVDs (grades 1 to 4), moderately degenerate IVDs (grades 5 to 8) and severely degenerate IVDs (grades 9 to 12), with five patient samples per category. Grading of IVD tissue was carried out as described by Sive and colleagues [28].

\section{Immunohistochemical procedure}

The immunohistochemical protocol was as previously published [20]. Briefly, following blocking of endogenous peroxidase and antigen retrieval with chymotrypsin $(1 \% \mathrm{w} / \mathrm{v})$ at $37^{\circ} \mathrm{C}$ for 20 minutes, sections were incubated overnight at $4^{\circ} \mathrm{C}$ with either $15 \mu \mathrm{g} / \mathrm{ml}$ primary goat anti-NGF, $15 \mu \mathrm{g} / \mathrm{ml}$ primary mouse anti-BDNF, $10 \mu \mathrm{g} / \mathrm{ml}$ primary goat anti-Trk-A or $8 \mu \mathrm{g} /$ $\mathrm{ml}$ primary mouse anti-Trk-B antibodies (R\&D Systems, Abingdon, UK). Negative controls were used in which respective goat and mouse IgGs (R\&D Systems) replaced the primary antibody. After washing, sections were incubated with biotinylated donkey anti-goat and goat anti-mouse secondary antibodies (Santa Cruz, CA, USA) at dilutions of $1 / 300$ and 1/ 400 , respectively, for 30 minutes at room temperature. Disclosure of secondary antibody binding was by the streptavidin-biotin complex (Dako, Cambridgeshire, UK) technique with 3,3'-diaminobenzidine tetrahydrochloride solution (Sigma, Poole, UK). Sections were counterstained with Mayers Haematoxylin (Raymond. A. Lamb, East Sussex, UK), were dehydrated and were mounted in XAM (BDH, Liverpool, UK).

\section{Analysis of immunohistochemical data}

For each tissue section, the different regions of the disc - NP, IAF and outer annulus fibrosus (OAF) - were first identified based on the cell morphology and the structure of the extracellular matrix. Up to a total of 400 cells were counted in each region of the IVD, and the number of positively stained cells was expressed as a percentage of the total number.

\section{Statistical analysis}

All data were tested for normality using the Shapiro-Wilke W method of analysis. As the data did not follow a normal distribution, a two-sided Mann-Whitney $\mathrm{U}$ test was performed to determine significance between the percentage of positive cells in the non-degenerate, moderate and severely degenerate disc samples. A Wilcoxin test was used to identify significance between the different regions of the IVD (NP, IAF and OAF). $P<0.05$ was considered significant.

\section{Effect of proinflammatory cytokines on neurotrophin and neuropeptide gene expression in nondegenerate and degenerate nucleus pulposus cells}

Primary NP cells were isolated from IVD samples obtained at surgery/postmortem, and ethical consent was obtained from the local ethical committees together with informed consent from the patient or relatives. NP cells were isolated from three non-degenerate IVDs (grades 1 to 2 ) of patients aged 37 to 61 years, and from three degenerate IVDs (grades 7 to 10) of patients aged 37 to 79 years.

\section{Nucleus pulposus cell extraction}

For cell extraction, NP tissue samples were minced and digested with $2 \mathrm{U} / \mathrm{ml}$ protease in DMEM and Ham's F-12 media for 30 minutes at $37^{\circ} \mathrm{C}$. To isolate NP cells, tissue samples were treated with $0.4 \mathrm{mg} / \mathrm{ml}$ collagenase type 1 (Gibco, Paisley, UK) for 4 hours in a shaking water bath at $37^{\circ} \mathrm{C}$. The resulting cell suspension was passed through a $40 \mu \mathrm{m}$ nylon cell strainer (BD Falcon, BD Biosciences, Oxford, UK) and spun at $300 \times g$ for 10 minutes. The cell pellet was washed twice with DMEM and Ham's F-12. Cells were seeded in vented culture flasks (BD Falcon) and were fed with DMEM (glucose and pyruvate) supplemented with $10 \% \mathrm{v} / \mathrm{v}$ heat-inactivated FCS (Gibco), $100 \mathrm{U} / \mathrm{ml}$ penicillin, $100 \mu \mathrm{g} / \mathrm{ml}$ streptomycin, $250 \mathrm{ng}$ amphotericin, $2 \mathrm{mM}$ glutamine and $50 \mu \mathrm{g} / \mathrm{ml}$ ascorbate (NP 10\% v/v serum-supplemented media). Cells were incubated at $37^{\circ} \mathrm{C}, 5 \%$ carbon dioxide and were fed with media every 3 to 4 days.

\section{Nucleus pulposus cell culture and treatment with proinflammatory cytokines}

Non-degenerate and degenerate NP cells were seeded in alginate to maintain their native phenotype. Cells expanded in monolayer culture (passage 4 or less) were trypsinised and resuspended in $1.2 \% \mathrm{w} / \mathrm{v}$ low-viscosity alginate (Sigma) in $0.15 \mathrm{M} \mathrm{NaCl}$ to give a cell density of 4 million cells $/ \mathrm{ml}$. The alginate/cell suspension was drawn into a $5 \mathrm{ml}$ syringe through a 21-gauge needle and drops of alginate/cell suspension were suspended in $102 \mathrm{mM} \mathrm{CaCl}_{2}$. Once formed, the alginate beads were placed on a rolling platform for $10 \mathrm{~min}$ utes at room temperature. This was followed by three 10minute washes in $0.15 \mathrm{M} \mathrm{NaCl}$ followed by one final wash in NP 10\% v/v serum-supplemented media. Beads were resuspended in NP $10 \% \mathrm{v} / \mathrm{v}$ serum-supplemented media and were plated into 12-well culture plates with approximately 10 to 15 beads per well. The plates were incubated for 14 days at $37^{\circ} \mathrm{C}, 5 \% \mathrm{CO}_{2}$ and the media was changed every 3 days.

For cytokine treatment, six alginate beads were added in triplicate to wells of a 12-well plate with $2 \mathrm{ml}$ media and were then treated with $10 \mathrm{ng} / \mathrm{ml} \mathrm{IL-1 \beta}$ (AMS Biotechnology Ltd, Abingdon, UK) or with $10 \mathrm{ng} / \mathrm{ml}$ TNF $\alpha$ (AMS Biotechnology Ltd) in NP $10 \% \mathrm{v} / \mathrm{v}$ serum-supplemented media for 48 -hour incubation at $37^{\circ} \mathrm{C}, 5 \% \mathrm{CO}_{2}$.

\section{Quantitative real-time PCR for NGF, BDNF and substance $P$ expression}

Post cytokine treatment RNA was extracted from NP cells, cDNA synthesised and quantitative real-time PCR carried out. Briefly, alginate beads were removed and $1 \mathrm{ml}$ dissolving buffer $(55 \mathrm{mM}$ sodium citrate, $30 \mathrm{mM}$ ethylenediamine 
tetraacetic acid and $0.15 \mathrm{M} \mathrm{NaCl}$ ) was added to each NP sample and incubated at room temperature for 10 minutes. The solution was then centrifuged and the cell pellet lysed with $1 \mathrm{ml} \mathrm{TRIzol}{ }^{\circledR}$ reagent. Superscript II enzyme was used to reverse-transcribe 500 ng RNA into cDNA in a standard $20 \mu \mathrm{l}$ reaction (Invitrogen, Paisley, UK).

Quantitative real-time PCR was carried out using the predesigned FAM MGB combined primer and the probe sets termed assays on demand for NGF, BDNF and substance $P$ from Applied Biosystems (Warrington, UK): NGF, Hs00171458_m1; BDNF, Hs00542425_s1; substance P, Hs00243225_m1. For each $25 \mu$ reaction, $2.5 \mu \mathrm{l}$ cDNA was added to $12.5 \mu \mathrm{l}$ Taqman Universal PCR Master Mix (Applied Biosystems), $1.25 \mu \mathrm{l}$ assays on demand and $8.75 \mu \mathrm{l}$ RNasefree molecular-grade water.

All cDNA samples and reactions were carried out in duplicate in ABI Prism 96-well plates (Applied Biosystems)). The quantitative real-time $P C R$ reactions were performed using an $A B I$ Prism 7000 detection system (Applied Biosystems). The procedure involved denaturation, Taq activation for 10 minutes at $95^{\circ} \mathrm{C}$, amplification with 40 PCR cycles of denaturation at $95^{\circ} \mathrm{C}$ for 15 seconds, followed by annealing and extension at $60^{\circ} \mathrm{C}$ for 1 minute. The $\mathrm{Ct}$ values generated were analysed as described both by Le Maitre and colleagues and by Livak and Schmittgen $[23,29]$.

\section{Statistical analysis of quantitative real-time PCR data}

To perform statistical analysis of all quantitative real-time PCR data, the $\mathrm{Ct}$ values from duplicates were averaged and the 2 $\Delta \mathrm{Ct}$ value calculated from the $\mathrm{Ct}$ difference. These values were then grouped together into untreated, IL-1 $\beta$-treated or TNF $\alpha$ treated nondegenerate and degenerate NP samples, and the statistical significance was determined between untreated and corresponding cytokine treatments. All data were tested for normality using the Shapiro-Wilke W method of analysis. As the data did not follow a normal distribution, a two-sided Mann-Whitney $U$ test was carried out to determine the significance between untreated and treated NP cell samples and also between non-degenerate and degenerate NP cell samples. $P<0.05$ was considered significant.

\section{Results}

\section{NGF and BDNF protein expression in the non-} degenerate and degenerate human IVD

Immunopositive staining was observed for both neurotrophins. Cellular staining for NGF and BDNF was identified in the native chondrocyte-like cells of the NP and IAF tissue and in the fibroblast-like cells of the OAF (Figures $1 \mathrm{a}$ to $1 \mathrm{f}$ and $2 \mathrm{a}$ to $2 \mathrm{f})$. The cell bodies of pyramidal neurons in human brain control tissue were also positive. Immunopositivity was observed in all regions of the IVD and was present in both non-degenerate and degenerate states.
Figure 1

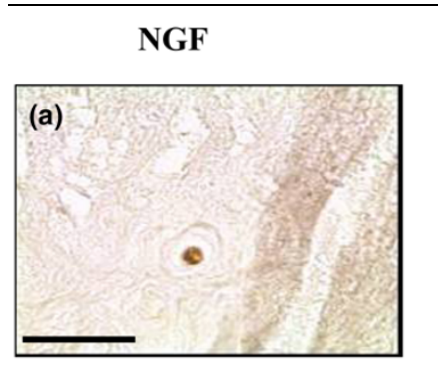

IgG Control
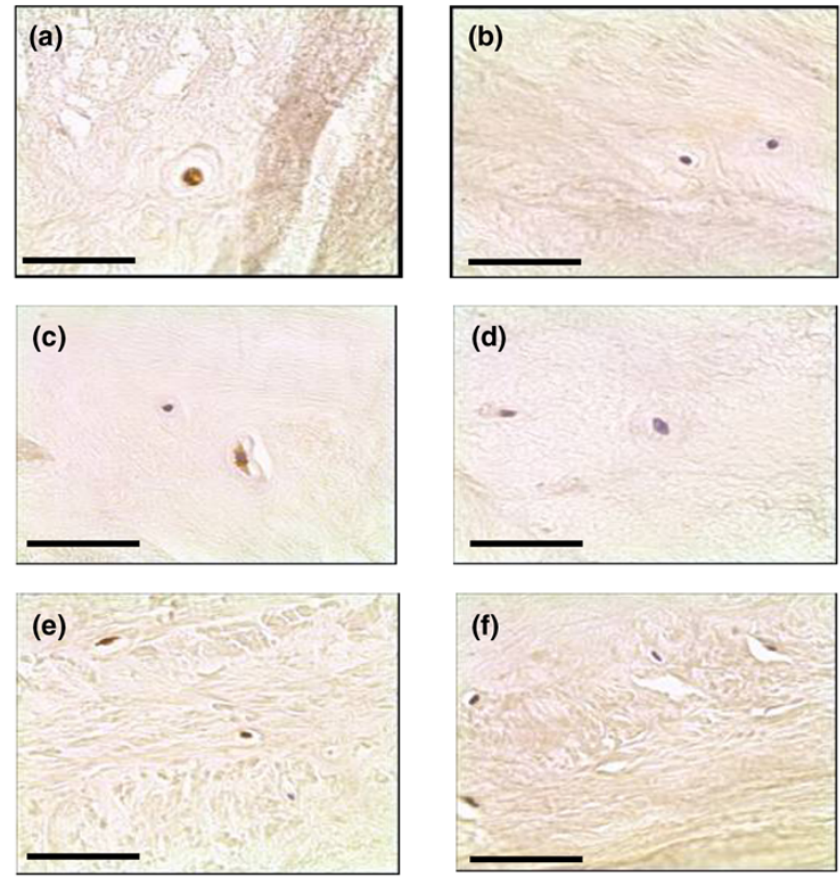

(d)

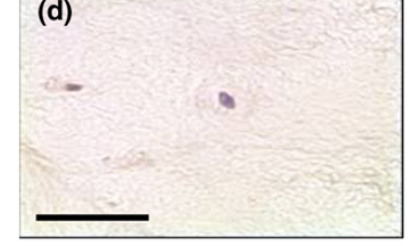

(f)

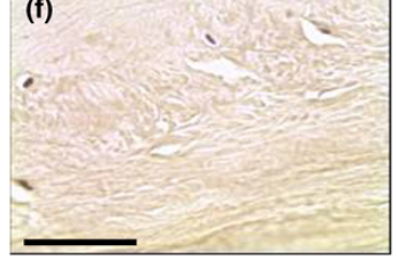

Nerve growth factor expression in human intervertebral disc tissue. Nerve growth factor (NGF) protein expression was identified in (a), (c) the chondrocyte-like cells of human nucleus pulposus and inner annulus fibrosus tissue, and (e) the fibroblast-like cells of the outer annulus fibrosus. (b), (d), (f) $\lg G$ controls were negative. Scale bar $=50 \mu \mathrm{m}$.

For NGF, expression was greater in NP and IAF tissue of moderate degenerate samples (grades 5 to 8 ) when compared with both non-degenerate and severely degenerate samples, although these differences were not significant (Figure 3a). For the NP, $39.5 \%, 56.9 \%$ and $43.3 \%$ of cells were positive in non-degenerate, moderately degenerate and severely degenerate IVD tissue, respectively. For the IAF, 49.2\%, $53.6 \%$ and $45.6 \%$ immunopositivity was identified in the nondegenerate and two degenerate states, respectively. For the OAF, $24.1 \%$ and $51.4 \%$ of cells were positive in moderately and severely degenerate IVD tissue, respectively. No significant differences were observed in cellular immunopositivity between the NP, IAF and OAF $(P>0.05)$.

An increase in BDNF protein expression was demonstrated with an increase in disease severity for all regions of the IVD (Figure 3b). For the NP, significance was observed between non-degenerate and severely degenerate tissue only: $12.5 \%$ compared with 39.8\% ( $P<0.05)$. For the IAF, however, significant differences were demonstrated for both the nondegenerate and moderately degenerate IVD compared with the severely degenerate IVD; $16.0 \%$ and $15.3 \%$ compared with $37.4 \%(P<0.05)$. No significant differences were observed between any of the disease states in the OAF $(P>$ 
Figure 2
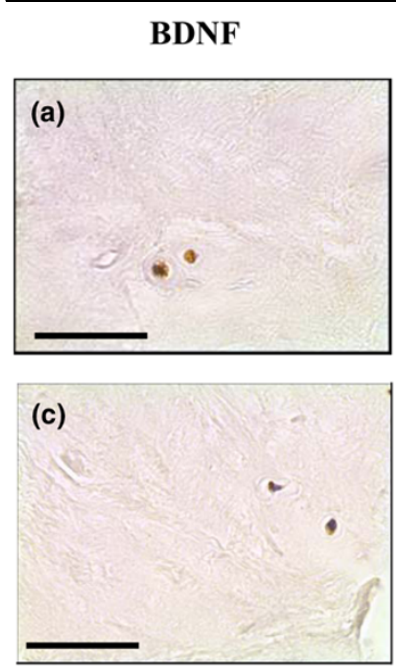

(e)

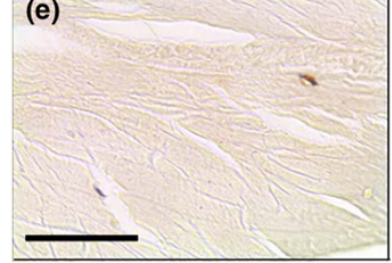

Brain-derived neurotrophic factor expression in human intervertebral disc tissue. Brain-derived neurotrophic factor (BDNF) protein expression was identified in (a), (c) the chondrocyte-like cells of human nucleus pulposus and inner annulus fibrosus tissue, and (e) the fibroblast-like cells of the outer annulus fibrosus. (b), (d), (f) $\lg G$ controls were negative. Scale bar $=50 \mu \mathrm{m}$.

0.05). Levels of immunopositivity in the NP and IAF differed significantly from that of the OAF $(P<0.05)$.

\section{Trk-A and Trk-B protein expression in the non- degenerate and degenerate human IVD}

Immunopositive staining for Trk-A and Trk-B was largely cellular in the chondrocyte-like cells of the NP and IAF, and also in the fibroblast-like cells of the OAF (Figures $4 c, d$ and $5 c, d$ ). Positive staining in control brain tissue was localised to blood vessels and to pyramidal cells for Trk-A and Trk-B, respectively.

Expression was detected in the NP, IAF and OAF of nondegenerate, moderately degenerate and severely degenerate IVD tissue in all regions of the IVD (Figure 6). For Trk-A, no significant increase in immunopositivity with disease severity was observed (Figure 6a), although there were significant differences between levels of immunopositivity in the NP and IAF, and also in the NP and IAF compared with the OAF $(P<0.05)$. For Trk-B, increased numbers of immunopositive cells were observed in severe degeneration in all regions of the IVD, although this was not significant (Figure 6b). There were sig-
Figure 3
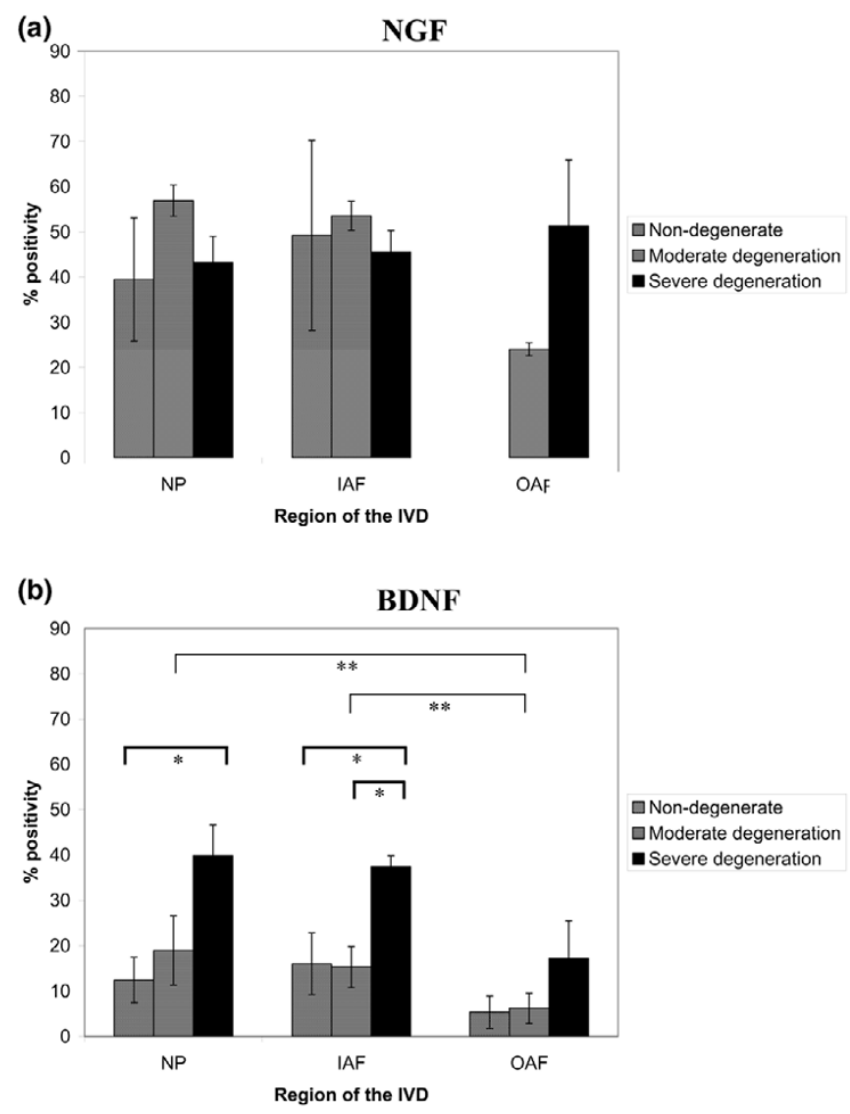

Neurotrophin immunopositivity in the nondegenerate and degenerate intervertebral disc. Histograms illustrating the percentage of (a) positive nerve growth factor (NGF) cells and (b) brain-derived neurotrophic factor (BDNF) immunopositive cells in the nucleus pulposus (NP), inner annulus fibrosus (IAF) and outer annulus fibrosus (OAF) regions of nondegenerate, moderately degenerate and severely degenerate intervertebral disc (IVD) tissue. *Significance between disease states,

${ }^{*}$ significance between regions of the IVD $(P<0.05)$. Data presented as the mean \pm standard error of the mean.

nificant differences in immunopositivity between the OAF and both the NP and IAF $(P<0.05)$.

\section{Effect of proinflammatory cytokines on neurotrophin and neuropeptide gene expression in non-degenerate and degenerate nucleus pulposus cells}

To examine the effect of disc-related proinflammatory cytokines on neurotrophin and neuropeptide expression in the IVD, cells derived from non-degenerate and degenerate NP patient samples were treated with either IL-1 $\beta$ or TNF $\alpha$. When these NP cells were treated with IL-1 $\beta$ for 48 hours, significant increases in the relative gene expression of NGF were observed $(P<0.05)$ : increases of eightfold for non-degenerate NP cells and of 5.5-fold for degenerate NP cells were demonstrated compared with untreated controls (Figure 7a). TNF $\alpha$ had little effect on the relative gene expression of NGF in nondegenerate and degenerate NP cells. The effects demonstrated by IL- $1 \beta$ and TNF $\alpha$ on NP samples were significantly 
Figure 4
Trk-A

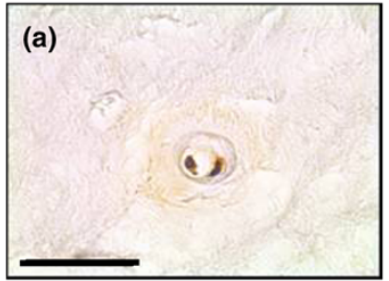

(c)
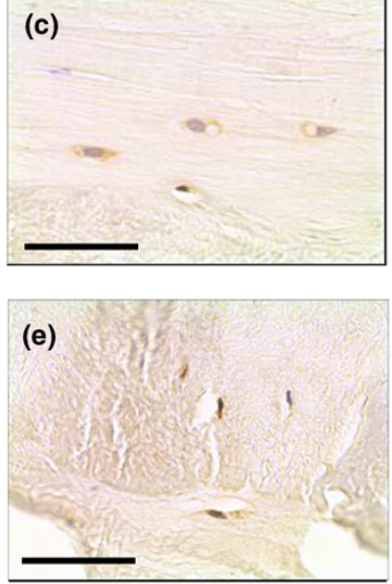

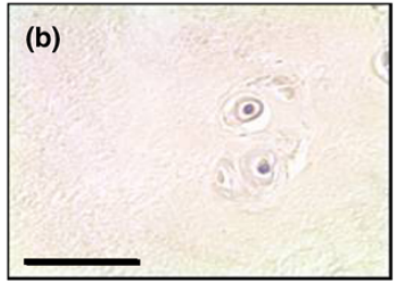

(d)

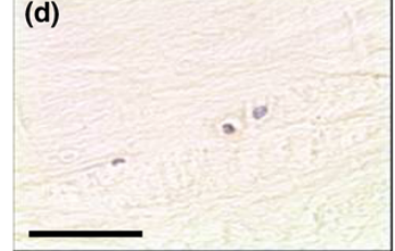

(f)

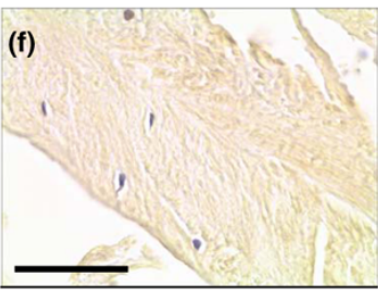

IgG Control

Trk-A expression in the human intervertebral disc tissue. Trk-A protein expression was identified in (a), (c) the chondrocyte-like cells nucleus pulposus and inner annulus fibrosus tissue, and (e) the fibroblast-like cells of the outer annulus fibrosus. (b), (d), (f) IgG controls were negative. Scale bar $=50 \mu \mathrm{m}$.

different from one another $(P<0.05)$, with IL-1 $\beta$ inducing greater NGF gene expression.

When observing the effects on BDNF gene expression, treatment with the proinflammatory cytokine IL-1 $\beta$ also led to significant increases - with changes of 5.5-fold in non-degenerate NP cells and fivefold in degenerate NP cells compared with untreated control cells $(P<0.05)$ (Figure $7 b)$. Increases in BDNF gene expression of twofold and 1.5 -fold were demonstrated after treatment with TNF $\alpha(P>0.05)$. Significant differences were again observed between IL-1 $\beta$ and $\mathrm{TNF} \alpha$ treatment for the NP samples tested $(P<0.05)$.

For the neuropeptide substance $\mathrm{P}$, treatment with IL-1 $\beta$ led to a decrease in relative gene expression - with changes of sixfold in non-degenerate NP cells and eightfold in degenerate NP cells compared with untreated controls (Figure 7c). This change was significant for degenerate NP cells only $(P<$ 0.05). Addition of TNF $\alpha$ had the opposite effect on substance $P$ gene expression: increases of twofold in non-degenerate NP cells and sixfold in degenerate NP cells were observed compared with untreated controls $(P>0.05)$. Significance was demonstrated between IL-1 $\beta$ and TNF $\alpha$ treatments for both NP samples $(P<0.05)$
Figure 5
Trk-B
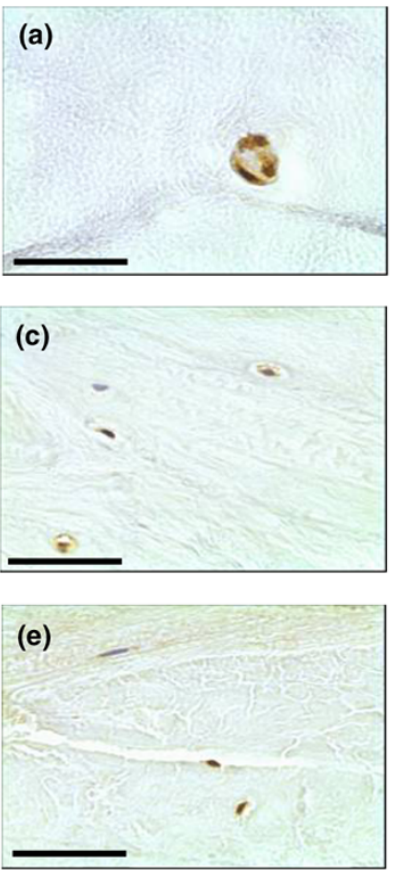

IgG Control
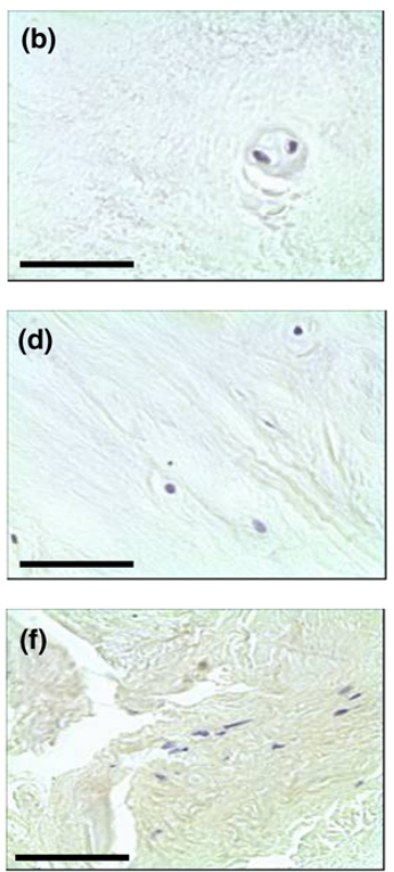

Trk-B expression in the human intervertebral disc tissue. Trk-A protein expression was identified in (a), (c) the chondrocyte-like cells nucleus pulposus and inner annulus fibrosus tissue, and (e) the fibroblast-like cells of the outer annulus fibrosus. (b), (d), (f) lgG controls were negative. Scale bar $=50 \mu \mathrm{m}$.

\section{Discussion}

A role for the neurotrophin family of growth factors, in particular NGF and BDNF, has been proposed in the IVD. There are no studies to date, however, which have examined an association between the expression of these two neurotrophins and the severity of disc degeneration. In the present study, an association between BDNF protein expression and disease severity was demonstrated - a greater number of positive disc cells was noted in all regions of severely degenerate samples (grades 9 to 12), which was significant for cells in the NP and IAF. For NGF, although a greater number of immunopositive cells were observed in the NP and IAF of disc samples of moderate degeneration and in the OAF of severely degenerate samples, these differences were not significant. These observations suggest that BDNF may be the more important neurotrophin in IVD degeneration driving pain-related processes as well as neuronal survival and innervation.

Few studies have examined the function of neurotrophin expression in cells of non-neural origin. Studies by Johnson and colleagues support the concept that disc cells, in particular cells from the degenerate IVD, produce nerve-promoting factors with the ability to induce neurite outgrowth [18]. Similarly, our previous work demonstrating the presence of Trk-Aexpressing nerves growing into the degenerate IVD 
Figure 6

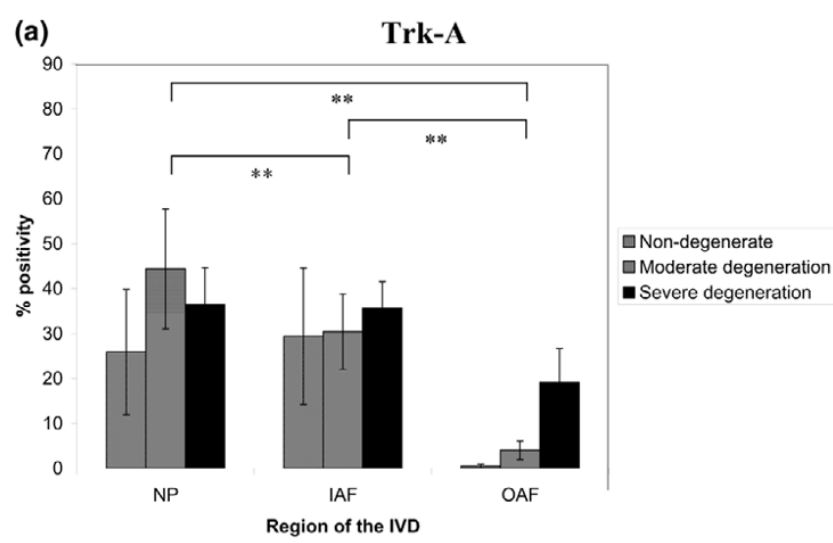

(b)

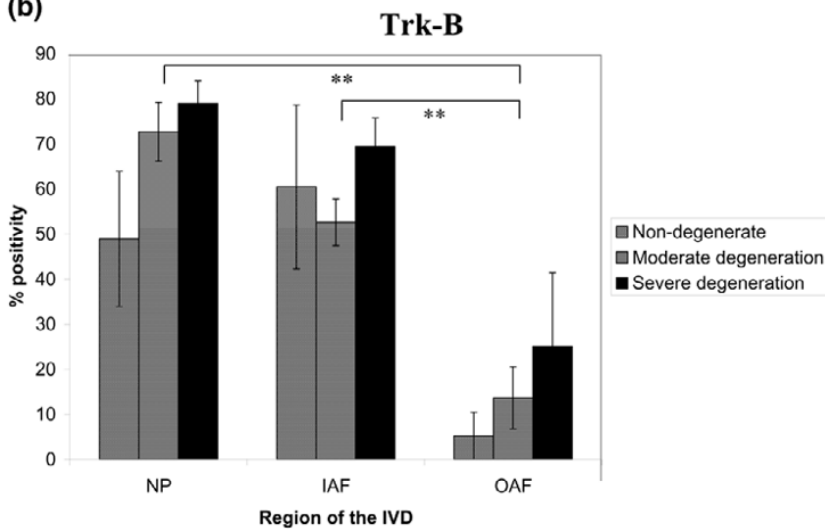

Neurotrophin receptor immunopositivity in the nondegenerate and degenerate intervertebral disc. Histograms illustrating the percentage of (a) positive Trk-A cells and (b) Trk-B immunopositive cells in the nucleus pulposus (NP), inner annulus fibrosus (IAF) and outer annulus fibrosus (OAF) regions of nondegenerate, moderately degenerate and severely degenerate intervertebral disc (IVD) tissue. ${ }^{* \star}$ Significance between regions of the IVD $(P<0.05)$. Data presented as the mean \pm standard error of the mean.

corroborates a role for neurotrophic factors, principally NGF, in the mechanisms associated with nerve ingrowth into the painful IVD [4]. Additionally, the high levels of NGF expression in both the non-degenerate and degenerate IVD perhaps point towards a function for NGF unrelated to nerve ingrowth or survival. Indeed, studies by Uchiyama and colleagues have highlighted a role for NGF in adaptation of disc cells to their acidic and hyperosmotic microenvironment via regulation of acidsensing ion channel 3 [30].

Our data show increased expression of BDNF with increasing severity of degeneration, which supports the recent findings of Gruber and colleagues [21]. This highlights a novel function for BDNF in possible innervation in the degenerate IVD, although further work elucidating its exact role is necessary and should include investigation of BDNF-responsive nerves within the degenerate IVD. Similarly a role for neurotrophic factors with regard to nociception in the painful IVD has yet to be elucidated.
Figure 7

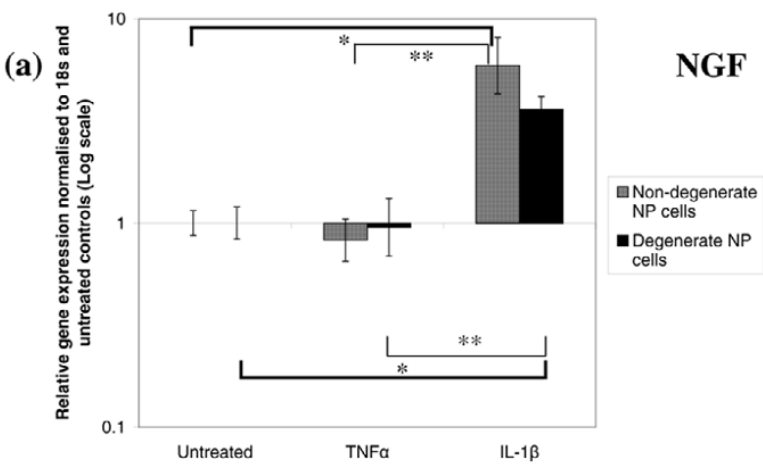

(b)

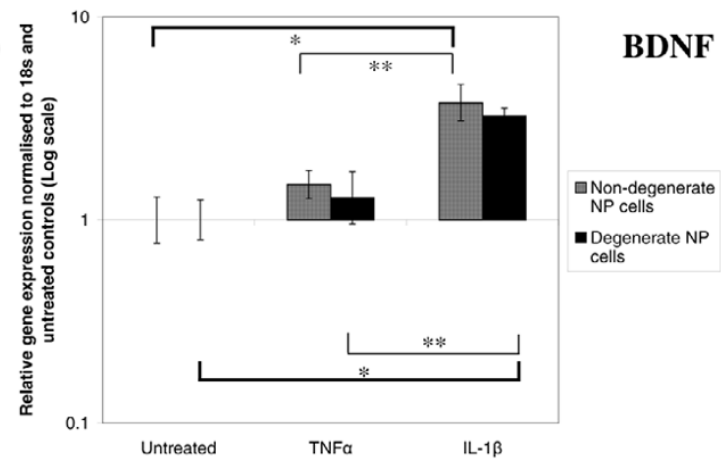

(c)

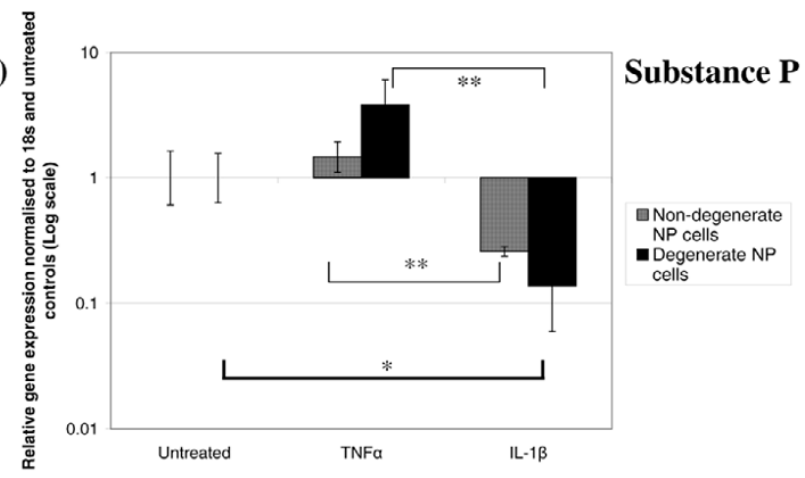

Effect of proinflammatory cytokines on neurotrophin and neuropeptide gene expression in nucleus pulposus cells. Histograms illustrating the relative gene expression of (a) nerve growth factor (NGF), (b) brainderived neurotrophic factor (BDNF) and (c) substance $P$ in nondegenerate and degenerate nucleus pulposus (NP) cells cultured with IL-1 $\beta$ and TNF $\alpha$ normalised to $18 \mathrm{~s}$ and untreated controls. *Significance between IL-1 $\beta$ treatment and untreated control, ** significance between $\mathrm{IL}-1 \beta$ and TNF $\alpha$ treatments $(P<0.05)$. Data presented as the mean \pm standard error of the mean.

Using a rat model of experimental IVD herniation, Onda and colleagues have highlighted a correlation between induction of NGF within the dorsal nerve root using surgical procedures and pain behaviour [31]. In a mouse model of skeletal pain and of bone healing, antibodies blocking NGF were shown to significantly reduce fracture pain-related behaviours [32]. The function of BDNF with regard to pain processes has focussed mainly on its role within the dorsal horn and central nervous system, with few studies examining effects peripherally. It is 
possible the neurotrophic factors expressed by IVD cells may have the ability to modulate each other's function. Studies by Zhao and colleagues suggest that NGF may regulate inflammatory pain in sensory nociceptive neurons in part through the expression of BDNF [33]. A relationship between NGF and BDNF within the IVD therefore requires futher investigation.

The present investigation also importantly highlights a possible function for neurotrophins and their receptors in disc cell biology. In non-degenerate, moderate and severely degenerate IVD tissue, the receptors Trk-A and Trk-B were expressed by the chondrocyte-like cells of the IVD, suggesting that neurotrophins in the IVD may exert autocrine effects on the disc cells themselves. Significant differences were observed between receptor expression in the different regions of the IVD: expression was significantly greater in the NP and IAF compared with the OAF. Some investigators have suggested that neurotrophin and receptor expression by articular chondrocytes may contribute to disease processes by influencing cell metabolism [15]. Work by Raucci and colleagues has demonstrated NGF to have an inhibitory effect on cell proliferation in chondrocytes [34], and similar effects have been observed in osteoblasts [35]. Neurotrophins may therefore play a role in matrix turnover and regulation of cell metabolism in the IVD.

The study undertaken here confirms a role for disc-related proinflammatory cytokines IL-1 $\beta$ and TNF $\alpha$ in the modulation of neurotrophin and neuropeptide expression in cells from the IVD seeded in a three-dimensional matrix. Treatment with IL-1 $\beta$ resulted in a significant increase in the relative gene expression of both NGF and BDNF in NP cells, with a greater increase in cells from non-degenerate IVD. This supports the work of Abe and colleagues, who demonstrated an increase in NGF protein and gene expression in NP cells seeded in monolayer and treated with IL-1 $\beta$ [19]. Indeed a number of studies have demonstrated regulation of NGF expression and NGFassociated pain processes by IL-1 $\beta[27,33]$. As a consequence, IL-1 $\beta$ may be an important factor with regard to upregulation of neurotrophin expression and nerve ingrowth by disc cells in the initial stages of disease. IL-1 $\beta$ expression in the IVD has also been shown to increase with disease severity [23], so it is reasonable to hypothesise that, as well as functioning to enhance catabolic processes, increasing amounts of IL-1 $\beta$ may also serve to perpetuate the degenerate disease IVD phenotype in terms of processes associated with nerve ingrowth and pain.

Unlike the results obtained by Abe and colleagues, however, the studies described here showed TNF $\alpha$ to have little effect on neurotrophin gene expression [19]. This may be as a consequence of differences in experimental procedures, as we cultured NP cells in alginate - which maintains a phenotype more representative of that seen in vivo - whereas Abe and colleagues treated NP cells cultured in monolayer [19]. Work by Hattori and colleagues has demonstrated a synergistic effect between TNF $\alpha$ and IL- $1 \beta$ in the stimulation of NGF from fibroblasts [36], and therefore whether the effects of TNF $\alpha$ on neurotrophin expression in the IVD also requires the presence of IL- $1 \beta$ remains to be investigated.

It is possible to hypothesise that substance $P$ may contribute to nociceptive processes within the degenerate IVD since expression of the pain-related neuropeptide and its receptor have been identified in both disc cells and nerves growing into the diseased IVD [5,37-39]. In the present study TNF $\alpha$ treatment resulted in an increase in substance $P$ expression, and this was greater in degenerate NP cells. An association of TNF $\alpha$ with substance $P$ expression and degeneration is supported by the work of Chubinskaya and colleagues, who have demonstrated downregulation of both genes in an anticatabolic disc model [40].

\section{Conclusion}

The results overall suggest a dual function for neurotrophins within the non-degenerate and degenerate IVD. Expression of NGF and increased expression of BDNF with degeneration identifies a possible role for these factors in perpetuation of nerve ingrowth into the degenerate IVD. Expression of the high-affinity receptors by cells of the non-degenerate and degenerate IVD, however, implicates an autocrine role for neurotrophins in disc cell metabolism. Enhancement of neurotrophin expression by IL-1 $\beta$ and neuropeptide expression by TNF $\alpha$ coupled with the increased expression of these proinflammatory cytokines in the degenerate IVD identifies new roles for IL-1 $\beta$ and TNF $\alpha$ in regulating nerve ingrowth and associated chronic low back pain. IL-1 $\beta$ may act as a key modulator of neurotrophin expression in the IVD, yet TNF $\alpha$ may have an influential role in regulation of nociception through substance $P$.

\section{Competing interests}

The authors declare that they have no competing interests.

\section{Authors' contributions}

DP participated in the design of the study, performed the majority of the laboratory work and analysis, and drafted the manuscript. AJF helped to secure funding, participated in the design of the study and interpretation of data, and assisted in the preparation of the final manuscript. JAH conceived the study, secured funding, contributed to its design and coordination, and participated in interpretation of the data and extensive preparation of the final manuscript. All authors read and approved the final manuscript.

\section{Acknowledgements}

The authors wish to thank Dr Aneta Pockert for her contribution to the IVD cell culture work. The present work was funded by a BBSRC Case Studentship in collaboration with Pfizer PLC, and was undertaken in the Human Tissue Profiling Laboratories of the Tissue Injury and Repair Research Group. 


\section{References}

1. Maniadakis N, Gray A: The economic burden of back pain in the UK. Pain 2000, 84:95-103.

2. Freemont AJ, Le Maitre C, Watkins A, Hoyland JA: Degeneration of intervertebral discs: current understanding of cellular and molecular events, and implications for novel therapies. Expert Rev Mol Med 2001, 29:1-10.

3. Le Maitre CL, Freemont AJ, Hoyland JA: Localization of degradative enzymes and their inhibitors in the degenerate human intervertebral disc. J Patho/ 2004, 204:47-54.

4. Freemont AJ, Watkins $A$, Le Maitre CL, Baird $P$, Jeziorska M, Knight MTN, Ross ERS, O'Brien JP, Hoyland JA: Nerve growth factor expression and innervation of the painful intervertebral disc. $J$ Pathol 2002, 197:286-292.

5. Freemont AJ, Peacock TE, Goupille P, Hoyland JA, O'Brien J, Jayson MIV: Nerve ingrowth into diseased intervertebral disc in chronic back pain. Lancet 1997, 350:178-181.

6. Johnson WEB, Caterson B, Eisenstein SM, Hynds DL, Snow DM, Roberts S: Human intervertebral disc aggrecan inhibits nerve growth in vitro. Arth Rheum 2002, 46:2658-2664.

7. Melrose J, Roberts S, Smith S, Menage J, Ghosh P: Increased nerve and blood vessel ingrowth associated with proteoglycan depletion in an ovine anular lesion model of experimental disc degeneration. Spine 2002, 27:1278-1285.

8. Jackson $\mathrm{HC}$ 2nd, Winkelmann RK, Bickel WH: Nerve endings in the human spinal column and related structures. J Bone Joint Surg Am 1966, 48:1272-1281.

9. Bogduk N, Tynan W, Wilson AS: The nerve supply to the human lumbar intervertebral discs. J Anat 1981, 132:39-56.

10. Fagan $A$, Moore $R$, Vernon Roberts $B$, Blumbergs $P$, Fraser $R$ : ISSLS prize winner: the innervation of the intervertebral disc: a quantitative analysis. Spine 2003, 28:2570-2576.

11. Aoki $Y$, Ohtori $S$, Takahashi $K$, Ino $H$, Takahashi $Y$, Chiba T, Moriya $\mathrm{H}$ : Innervation of the lumbar intervertebral disc by nerve growth factor-dependent neurons related to inflammatory pain. Spine 2004, 29:1077-1081.

12. Ohtori S, Takahashi $\mathrm{K}$, Moriya $\mathrm{H}$ : Existence of brain-derived neurotrophic factors and vanilloid receptor subtype 1 immunoreactive sensory DRG neurons innervating L5/6 intervertebral discs in rats. J Orthop Sci 2003, 8:84-87.

13. Pezet S, McMahon SB: Neurotrophins: mediators and modulators of pain. Annu Rev Neurosci 2006, 29:507-538.

14. Yamashiro T, Fukunaga T, Yamashita K, Kobashi N, TakanoYamamoto T: Gene and protein expression of brain-derived neurotrophic factor and TrkB in bone and cartilage. Bone 2001, 28:404-409.

15. lannone F, De Bari C, Dell'Accio F, Covelli M, Patella V, Lo Bianco G, Lapadula G: Increased expression of nerve growth factor (NGF) and high affinity NGF receptor (p140 TrkA) in human osteoarthritic chondrocytes. Rheumatology (Oxford) 2002, 41:1413-1418.

16. Gigante A, Bevilacqua C, Pagnotta A, Manzotti S, Toesca A, Greco F: Expression of NGF, Trka and p75 in human cartilage. Eur J Histochem 2003, 47:339-344.

17. Rihl M, Kruithof E, Barthel C, De Keyser F, Veys EM, Zeidler H, Yu DT, Kuipers JG, Baeten D: Involvement of neurotrophins and their receptors in spondyloarthritis synovitis: relation to inflammation and response to treatment. Ann Rheum Dis 2005, 64:1542-1549.

18. Johnson WEB, Sivan S, Wright KT, Eisenstein SM, Maroudas A, Roberts S: Human intervertebral disc cells promote nerve growth over substrata of human intervertebral disc aggrecan. Spine 2006, 31:1187-1193

19. Abe Y, Akeda K, An HS, Aoki Y, Pichika R, Muehleman C, Kimura T, Masuda K: Proinflammatory cytokines stimulate the expression of nerve growth factor by human intervertebral disc cells. Spine 2007, 32:635-642.

20. Boyd LM, Richardson WJ, Chen J, Kraus VB, Tewari A, Setton LA: Osmolarity regulates gene expression in intervertebral disc cells determined by gene array and real-time quantitative RTPCR. Ann Biomed Eng 2005, 33:1071-1077.

21. Gruber HE, Ingram JA, Hoelscher GL, Zinchenko N, Norton HJ, Hanley EN Jr: Brain-derived neurotrophic factor and its receptor in the human and sand rat intervertebral disc. Arthritis Res Ther 2008, 10:R82.
22. Olmarker K: Neovascularisation and neoinnervation of subcutaneously placed nucleus pulposus and the inhibitory effects of certain drugs. Spine 2005, 30:1501-1504.

23. Le Maitre CL, Freemont AJ, Hoyland JA: The role of interleukin-1 in the pathogenesis of human intervertebral disc degeneration. Arthritis Res Ther 2005, 7:R732-R745.

24. Le Maitre CL, Hoyland JA, Freemont AJ: Catabolic cytokine expression in degenerate and herniated human intervertebral discs: IL-1 $\beta$ and TNF $\alpha$ expression profile. Arthritis Res Ther 2007, 9:R77.

25. Hoyland JA, Le Maitre CL, Freemont AJ: Investigation of the role of IL-1 and TNF in matrix degradation in the intervertebral disc. Rheumatology (Oxford) 2008, 47:809-814.

26. Kemi C, Grunewald J, Eklund A, Höglund CO: Differential regulation of neurotrophin expression in human bronchial smooth muscle cells. Respir Res 2006, 7:18.

27. Manni L, Lundeberg T, Fiorito S, Bonini S, Vigneti E, Aloe L: Nerve growth factor release by human synovial fibroblasts prior to and following exposure to tumour necrosis factor-alpha, interleukin-1 beta and cholecystokinin-8: the possible role of NGF in the inflammatory response. Clin Exp Rheumatol 2003, 21:617-624.

28. Sive Jl, Baird P, Jeziorsk M, Watkins A, Hoyland JA, Freemont AJ: Expression of chondrocyte markers by cells of normal and degenerate intervertebral discs. Mol Pathol 2002, 55:91-97.

29. Livak KJ, Schmittgen TD: Analysis of relative gene expression data using real-time quantitative PCR and the 2(-Delta Delta C(T)) method. Methods 2001, 25:402-408.

30. Uchiyama Y, Cheng CC, Danielson KG, Mochida J, Albert TJ, Shapiro IM, Risbud MV: Expression of acid-sensing ion channel 3 (ASIC3) in nucleus pulposus cells of the intervertebral disc is regulated by p75NTR and ERK signalling. J Bone Miner Res 2007, 22:1996-2006.

31. Onda A, Murata Y, Rydevik B, Larsson K, Kikuchi S, Olmarker K: Nerve growth factor content in dorsal root ganglion as related to changes in pain behaviour in a rat model of experimental lumbar disc herniation. Spine 2005, 30:188-193.

32. Koewler NJ, Freeman KT, Buus RJ, Herrera MB, Jimenez-Andrade JM, Ghilardi JR, Peters CM, Sullivan LJ, Kuskowski MA, Lewis JL, Mantyh PW: Effects of a monoclonal antibody raised against nerve growth factor on skeletal pain and bone healing after fracture of the C57BL/6J mouse femur. J Bone Miner Res 2007, 22:1732-1742.

33. Zhao J, Seereeram A, Nassar MA, Levato A, Pezet S, Hathaway G, Morenilla-Palao C, Stirling C, Fitzgerald M, McMahon SB, Rios M Wood JN, London Pain Consortium: Nociceptor-derived brainderived neurotrophic factor regulates acute and inflammatory but not neuropathic pain. Mol Cell Neurosci 2006, 31:539-548.

34. Raucci A, Laplantine E, Mansukhani A, Basilico C: Activation of the ERK1/2 and p38 mitogen-activated protein kinase pathways mediates fibroblast growth factor-induced growth arrest of chondrocytes. J Biol Chem 2004, 279:1747-1756.

35. Yada M, Yamaguchi K, Tsuji T: NGF stimulates differentiation of osteoblastic MC3T3-E1 cells. Biochem Biophys Res Commun 1994, 205:1187-1193

36. Hattori A, Iwasaki S, Murase K, Tsujimoto M, Sato M, Hayashi K, Kohno M: Tumour necrosis factor is markedly synergistic with interleukin 1 and interferon-gamma in stimulating the production of nerve growth factor in fibroblasts. FEBS Lett 1994 340:177-180

37. Palmgren T, Grönblad M, Virri J, Kääpä E, Karaharju E: An immunohistochemical study of nerve structures in the anulus fibrosus of human normal lumbar intervertebral discs. Spine 1999 , 24:2075-2079.

38. Ozawa T, Aoki Y, Ohtori S, Takahashi K, Chiba T, Ino H, Moriya H: The dorsal portion of the lumbar intervertebral disc is innervated primarily by small peptide-containing dorsal root ganglion neurons in rats. Neurosci Lett 2003, 344:65-67.

39. Ohtori S, Inoue G, Koshi T, Ito T, Doya H, Moriya H, Takahashi K: Substance $P$-saporin down-regulates substance $P$ receptor immunoreactive sensory dorsal root ganglion neurons innervating the lumbar intervertebral discs in rats. Spine 2006, 31:2987-2991.

40. Chubinskaya S, Kawakami M, Rappoport L, Matsumoto T, Migita $\mathrm{N}$, Rueger DC: Anti-catabolic effect of OP-1 in chronically compressed intervertebral discs. J Orthop Res 2007, 25:517-530. 